\title{
Gas Permeation Properties of Conducting Polymer/Porous Media Composite Membranes II
}

\author{
Kensuke Kamada, * Jun Kamo, Akira Motonaga, \\ Tadashi Iwasaki, and Hiroshi Hosokawa \\ Central Research Laboratories, Mitsubishi Rayon Co., Ltd., Ohtake, Hiroshima 739-06, Japan
}

(Received November 29, 1993)

\begin{abstract}
To get a gas separation membrane of high performance by a mechanism of surface flow through porous membranes, $N$-methylpyrrole was polymerized by the chemical oxidative method in the micro-pores of a ceramic filter which had an asymmetric structure. Gas permeation rates of $\mathrm{O}_{2}$ and $\mathrm{N}_{2}$ were measured with composite membranes using air as feed gas. One of them showed that the gas permeation rate of $\mathrm{O}_{2}$ was $1.31 \times 10^{-4}\left(\mathrm{~cm}^{3}(\mathrm{STP}) \cdot \mathrm{cm}^{-2} \cdot \mathrm{s}^{-1}\right.$. $\left.\mathrm{cmHg}^{-1}\right)$ and the separation factor $\alpha\left(\mathrm{O}_{2} / \mathrm{N}_{2}\right)$, 3.9. The gas permeation rate was compared with that of the Vycor composite membrane reported in the previous paper. The gas permeation rate of the composite membranes obtained in these studies appeared proportional to the inverse of the effective thickness of membrane without reduction of permselectivity. With the composite membrane, gas permeation rate and $\alpha$ were measured from room temperature to $120^{\circ} \mathrm{C}$. High permselectivity was found even at $120^{\circ} \mathrm{C}$. To make clear the interaction between gas components permeating membrane at the same time, gas permeation rates were evaluated while varying the feed gas pressure for both pure gas and mixed gas (air).

KEY WORDS Gas / Permeation / Poly $(N$-methylpyrrole) / Composite /

Membrane / Ceramic / $\mathrm{O}_{2} / \mathrm{N}_{2}$ /
\end{abstract}

The previous paper $^{1}$ reported composite membranes prepared by compositing the micro-porous glass (Vycor glass) with some kinds of conducting polymers, such as polypyrrole, poly ( $N$-methylpyrrole), and polyaniline. The composite membranes had selective gas permeabilities, especially a larger gas permeation rate (abbreviated GPR hereafter) for $\mathrm{O}_{2}$ than $\mathrm{N}_{2}$. The mechanism of gas permeation through the composite membranes was considered surface flow from various experimental results. The best properties attained were those of Vycor glass/poly $(N$-methylpyrrole) composite membrane, No. 7 (Table II in the previous paper), which showed that the $\operatorname{GPR}\left(\mathrm{O}_{2}\right)$ was $1.5 \times 10^{-6}\left(\mathrm{~cm}^{3} \cdot \mathrm{cm}^{-2} \cdot \mathrm{s}^{-1}\right.$. $\left.\mathrm{cmHg}{ }^{-1}\right)$ and the separation factor $\alpha\left(\mathrm{O}_{2} / \mathrm{N}_{2}\right)$, 3.1. The properties were much better compared with silicon rubber membranes having the same thickness.

With synthetic polymers, Uchida et al. ${ }^{2}$ recently developed a novel multi-layered hollow fiber membrane for gas separation, the active layer of which was $c a .0 .5 \mu \mathrm{m}$ in thickness. $\operatorname{GPR}\left(\mathrm{O}_{2}\right)$ of the hollow fiber attained $c a .1 .0 \times 10^{-4}$ and $\alpha$ was about 2 . For a porous composite membrane through which gas permeates with the surface flow, it is important to investigate the effects of membrane thickness on GPR and $\alpha$ to design a high performance membrane.

In this study, composite membranes were prepared by compositing a ceramic filter having a thin active layer with poly $(N$-methylpyrrole $)$ in the same way as in the previous paper and the gas permeation properties were investi-

\footnotetext{
* To whom correspondence should be addressed.
} 
gated. A composite membrane of Vycor glass was also prepared and the pressure dependence of GPR was studied with pure gas and mixed gas (air).

\section{EXPERIMENTAL}

\section{Material}

Reagent grade materials were used without further purification for chemical oxidative polymerization. $\mathrm{N}$-Methylpyrrole, ferric chloride $\left(\mathrm{FeCl}_{3} \cdot 6 \mathrm{H}_{2} \mathrm{O}\right)$ and acetonitrile were used as monomer, oxidizing agent and solvent, respectively. A micro-porous glass tube, Vycor \#7930 (produced by Corning Glass Works) the same one as in the previous report and a ceramic tube filter for ultrafiltration, MEMBRALOX (purchased from Toshiba Ceramic Co., Ltd.), were used as support media to prepare composite membranes on which $\mathrm{N}$ methylpyrrole was polymerized. The outer and inner diameters of the ceramic tube filter were $19 \mathrm{~mm}$ and $15 \mathrm{~mm}$, respectively. The cylindrical membrane was thus $2 \mathrm{~mm}$ in thickness.

According to the catalog ${ }^{3}$, the ceramic filter consists of porous $\mathrm{Al}_{2} \mathrm{O}_{3}$ having an asymmetric structure of three layers. The thin top layer is an active layer having pores of $4 \mathrm{~nm}$ in size, supported by a middle layer having pores of several times larger than those of the top layer. The middle layer is supported by a third layer having pores of $15 \mu \mathrm{m}$ in size. The cross section near the inner surface of the tube was observed with scanning electron micrography as shown in Photograph 1. The top layer is $c a .16 \mu \mathrm{m}$ in thickness supported with the middle layer having $c a$. $20-30 \mu \mathrm{m}$ in thickness and the major part of the membrane consists of the third layer with large pores.

\section{Preparation of Composite Membranes}

Composite membranes were prepared by the same procedure reported in the previous paper. In the case of Vycor glass as a support medium, the concentrations of the monomer and oxidant solutions were fixed $0.3 \mathrm{~mol} \cdot \mathrm{dm}^{-3}$.

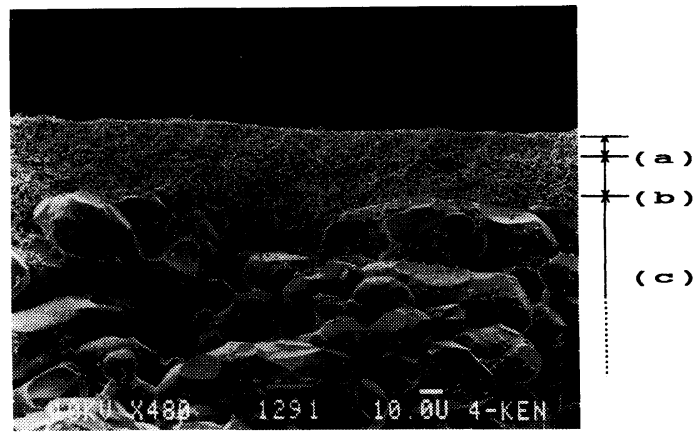

Photograph 1. Scanning electron micrograph of a cross section of the ceramic filter: $\times 480$ white bar, $10 \mu \mathrm{m}$; (a), thin top layer; (b), middle layer; (c), third layer with large pores.

The Vycor glass was immersed in the oxidant solution for $10 \mathrm{~min}$ and then in the monomer solution for $5 \mathrm{~min}$. The polymerization procedure was repeated 3 times. In the case of the ceramic filter as a support medium, the concentrations of the monomer and oxidant solutions were varied from 0.2 to $0.6 \mathrm{~mol}$. $\mathrm{dm}^{-3}$. The time of immersion in the oxidant and monomer solutions was fixed at $10 \mathrm{~min}$. The polymerization procedure was repeated 3 to 4 times.

\section{Measurement of Gas Permeation Rate (GPR)}

GPRs of the composite membranes were measured with the same equipment as in the previous paper. Both open ends of the cylindrical ceramic composite membrane having $20 \mathrm{~mm}$ effective length were connected to stainless steel tubes with adhesive. The test gas permeated through the membrane from the inner side of pipe to the outer side. For the Vycor composite membrane, the dimension of a test piece was the same as in the previous paper. Dried air, $\mathrm{O}_{2}$ and $\mathrm{N}_{2}$ were used as test gases and the feed pressure was varied to $3.8 \times 10^{3}$ Torr $(5 \mathrm{~atm})$. GPRs were ordinarily measured at room temperature $\left(\mathrm{ca} .25^{\circ} \mathrm{C}\right)$ and at variable temperature up to $120^{\circ} \mathrm{C}$ heating the cell part in the thermostated oven. GPR was calculated as the same unit as in the previous paper, i.e., $\mathrm{cm}^{3} \cdot \mathrm{cm}^{-2} \cdot \mathrm{s}^{-1} \cdot \mathrm{cmHg}^{-1}$. 


\section{RESULTS AND DISCUSSION}

\section{GPR of Ceramic Composite Membranes}

Several composite membranes were prepared by changing polymerization conditions with the porous ceramic filter, the structure of which is shown in Photograph 1. $\operatorname{GPR}\left(\mathrm{O}_{2}\right)$ and GPR $\left(\mathrm{N}_{2}\right)$ of the membranes were measured at the same time with air as feed gas under constant pressure 1 atm (760 Torr). The results are summarized in Table I with the polymerization conditions. The separation factor $\alpha\left(\mathrm{O}_{2} / \mathrm{N}_{2}\right)$ was calculated from the ratio of $\operatorname{GPR}\left(\mathrm{O}_{2}\right)$ to $\operatorname{GPR}\left(\mathrm{N}_{2}\right)$. GPRs of the ceramic filter, No. 1, and composite membrane, 2, were so large that the volume of gas permeated was measured with a gas flow meter and the composition of gas was not analyzed.

As shown in Table I, GPR(air) of the ceramic filter, No. 1 was about $10^{4}$ times that of Vycor glass (No. 1 of Table II in the previous paper). This may be due the asymmetric structure of the filter which has a thin active layer (ca. $16 \mu \mathrm{m}$ in thickness), (a), as shown in Photograph 1. According to the catalog, ${ }^{3}$ the active layer has pores of $4 \mathrm{~nm}$ in size, so the gas flow through the ceramic filter is a Kundsen flow, the same as Vycor glass. As polymerization proceeded, GPR of the composite membranes decreassed and $\alpha$ increased. The composite membrane, No. 5 showed excellent permselectivity for $\mathrm{O}_{2}$ and a large $\operatorname{GPR}\left(\mathrm{O}_{2}\right)$. It was observed in the previous report on the Vycor glass that there were ideal conditions for polymerization to give a high performance membrane. The same was occurred in this case and ideal modification of the surface of pores with polymer was attained in case of the composite membrane, No. 5.

Yoshimizu et al. ${ }^{4}$ reported the gas $\left(\mathrm{O}_{2}\right.$ and $\mathrm{N}_{2}$ ) permeation properties of polypyrrole membrane obtained by the electro-polymerization method. According to their data, without charging the membrane with electricity, the permeability coefficient of $\mathrm{O}_{2}, \mathrm{P}\left(\mathrm{O}_{2}\right)$, was $1.17 \times 10^{-11}\left(\mathrm{~cm}^{3} \cdot \mathrm{cm} \cdot \mathrm{cm}^{-2} \cdot \mathrm{s}^{-1} \cdot \mathrm{cmHg}^{-1}\right)$ and the separation factor $\alpha\left(\mathrm{O}_{2} / \mathrm{N}_{2}\right)$ was 2.4. Assuming the gas permeation properties of $\operatorname{poly}(N$ methylpyrrole) membrane are the same as those of polypyrrole, the membrane thickness of poly $(N$-methylpyrrole), $t$, having the same $\operatorname{GPR}\left(\mathrm{O}_{2}\right)$ of the composite membrane, No. 5, was estimated as $1.17 \times 10^{-11} / 1.3 \times 10^{-4}(=$ $0.9 \mathrm{~nm})$. The fraction of the pore area of the ceramic filter is less than 1 and the gas permeation through $\mathrm{Al}_{2} \mathrm{O}_{3}$ is negligible small. $T$ must thus be less than the above value, $0.9 \mathrm{~nm}$. Thus, the mechanism of gas flow through the composite membrane, No. 5, is considered the following three cases shown in Figure 1.

a) Kundsen flow $\gg$ Surface flow

b) Surface flow $\gg$ Knudsen flow

Table I. Polymerization conditions and GPRs of ceramic composite membranes

\begin{tabular}{|c|c|c|c|c|c|}
\hline \multirow{2}{*}{$\begin{array}{l}\text { Expt } \\
\text { No. }\end{array}$} & \multirow{2}{*}{$\begin{array}{l}\text { Concn. of }{ }^{b} \\
\text { monomer }\end{array}$} & \multirow{2}{*}{$\begin{array}{l}\text { No. of } \\
\text { polymn. }\end{array}$} & \multicolumn{2}{|c|}{$\mathrm{GPR}^{\mathrm{c}}$} & \multirow{2}{*}{$\alpha\left(\mathrm{O}_{2} / \mathrm{N}_{2}\right)$} \\
\hline & & & $\mathrm{O}_{2}$ & $\mathrm{~N}_{2}$ & \\
\hline 1 & - & - & \multicolumn{2}{|c|}{$2.1 \times 10^{-1}$} & - \\
\hline 2 & 0.2 & 3 & \multicolumn{2}{|c|}{$6.6 \times 10^{-3}$} & - \\
\hline 3 & 0.4 & 4 & $4.1 \times 10^{-5}$ & $3.3 \times 10^{-5}$ & 1.2 \\
\hline $4^{a}$ & 0.4 & 3 & $5.9 \times 10^{-6}$ & $3.9 \times 10^{-6}$ & 1.5 \\
\hline 5 & 0.6 & 3 & $1.3 \times 10^{-4}$ & $3.3 \times 10^{-5}$ & 3.9 \\
\hline 6 & 0.6 & 4 & $3.6 \times 10^{-5}$ & $2.0 \times 10^{-5}$ & 1.8 \\
\hline
\end{tabular}

a Membrane No. 2, was used as the starting medium.

b The unit is moldm ${ }^{-3}$. The concentration of oxidant is the same as monomer.

c The feed gas is air at 760 Torr. 

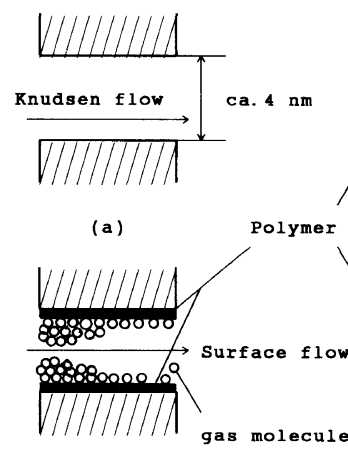

(b)

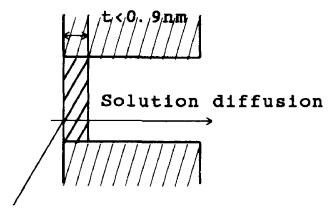

(c)

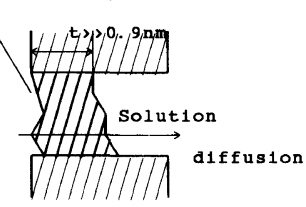

(d)
Figure 1. Schematic representation of a gas flow through composite membrane (a) Knudsen flow dominates, (b) surface flow dominates, (c) solution-diffusion flow, $t$ : membrane thickness, (d) polymer cloggs pore.

c) Solution-Diffusion flow, $t<0.9 \mathrm{~nm}$.

The separation factor $\alpha\left(\mathrm{O}_{2} / \mathrm{N}_{2}\right)$ of No. 5 was much larger than the value estimated from Knudsen flow, i.e., $0.93\left(=(28 / 32)^{1 / 2}\right)$ and was larger than the value, 2.4 , evaluated with the polypyrrole membrane. The gas flow through the composite membrane, No. 5, is thus dominated by surface flow, case (b). Other reasons which support the surface flow mechanism are 1) it is difficult to form a membrane having thickness thinner than $0.9 \mathrm{~nm}$ by chemical oxidative polymerization, 2) characteristic pressure dependence of GPR and 3) a minor contaminant gas has a very large influence on GPR.

Composite membranes, No. 3, 4, and 6, might not have the ideal structure (b) in Figure 1 , but structure (d) where the polymer clogs the pore or structure (a) where polymerization dose not occur effectively. Actually, both structures (a) and (d) might coexist in the composite membranes and GPR and $\alpha$ vary with complexity by polymerization.

According to Horiguchi et al., ${ }^{5}$ the surface flow is expressed by two dimensional form of Fick's 1st Law,

$$
N_{\mathrm{S}}=-K \cdot D_{\mathrm{S}}\left(\mathrm{d} C_{\mathrm{S}} / \mathrm{d} l\right)
$$

where $N_{\mathrm{S}}$ is the flow rate of the adsorbate, $C_{\mathrm{S}}$ is the surface concentration of the adsorbate, $D_{\mathrm{S}}$ is the surface diffusion coefficient, $l$ is the length of diffusion and $K$ is the constant determined by the membrane structure. Introducing pressure $P$ as a variable and assuming that the surface diffusion is an activated process, eq 1 may be written as ${ }^{5}$

$$
\begin{aligned}
N_{\mathrm{S}}= & -K \cdot D_{\mathrm{SO}} \\
& \cdot \exp (-E / R T) \cdot\left(\mathrm{d} C_{\mathrm{S}} / \mathrm{d} P\right) \cdot(\mathrm{d} P / \mathrm{d} l)
\end{aligned}
$$

where $D_{\text {so }}$ is the temperature independent diffusion coefficient, $E$ is the activation energy for diffusion and $R$ is the gas constant.

Assuming one dimensional diffusion in the composite membrane, $N_{\mathrm{S}}$ should be proportional to $1 / L$, where $L$ is an effective membrane thickness. The pore size of the active layer of the ceramic filter, $4 \mathrm{~nm}$, is very close to that of Vycor glass $\left(4.4 \mathrm{~nm}^{1}\right)$. Therefore, assuming membrane structures of both composite membranes which influence the gas permeation to be roughly the same, the gas flow ratio of the both composite membranes should be equal to the ratio of $(L)^{-1}$. The effective thicknesses of the Vycor and ceramic composite membrane are $1.1 \mathrm{~mm}$ and $16 \mu \mathrm{m}$ respectively, so the ratio, $\operatorname{GPR}\left(\mathrm{O}_{2}\right)$ of the ceramic composite membrane to that of the Vycor's, should be $(0.016)^{-1} /$ $(1.1)^{-1}$, i.e., 69. The gas flow ratio obtained experimentally is $\left(1.31 \times 10^{-4}\right) /\left(1.5 \times 10^{-6}\right)$, i.e., 87.

The two values coincide quite well, which leads to the important conclusion that in the case of gas separation by a surface flow mechanism, GPR is proportional to the inverse of the membrane thickness without reduction of permselectivity.

\section{Effect of Pressure on GPR}

The previous study showed the pressure of feed gas to have large influence on GPR of composite membranes. To investigate this in more detail, GPRs of $\mathrm{O}_{2}$ and $\mathrm{N}_{2}$ through the Vycor glass/poly( $N$-methylpyrrole) composite membrane were measured with pure gas and 


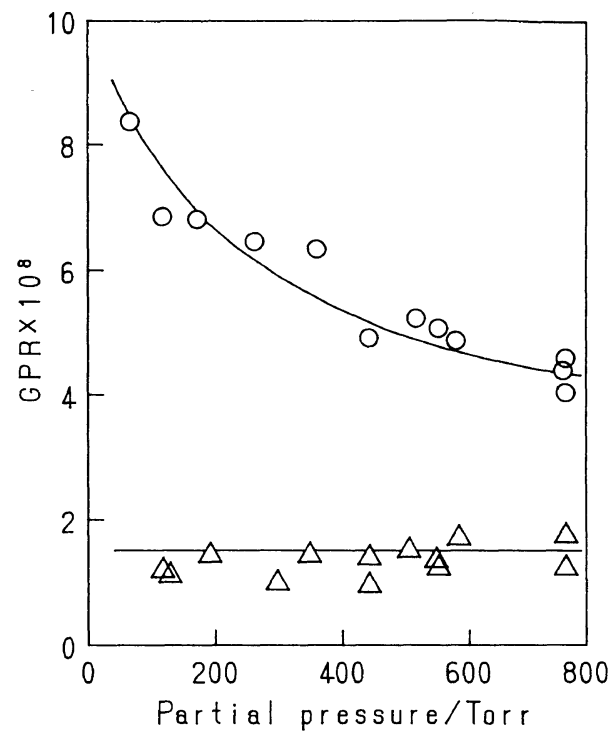

Figure 2. GPR vs. feed gas pressure for the Vycor glass composite membrane: feed gas, pure gas; $(\mathrm{O}), \operatorname{GPR}\left(\mathrm{O}_{2}\right)$; $(\triangle), \operatorname{GPR}\left(\mathrm{N}_{2}\right)$.

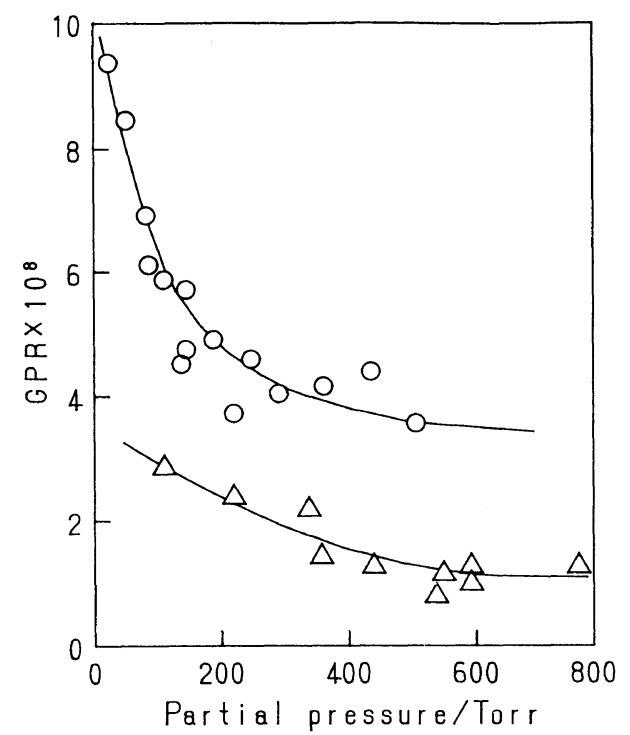

Figure 3. GPR vs. feed gas pressure for the Vycor glass composite membrane: feed gas, air; $(\mathrm{O}), \operatorname{GPR}\left(\mathrm{O}_{2}\right) ;(\triangle)$, $\operatorname{GPR}\left(\mathrm{N}_{2}\right)$.

mixed gas (air) varying the partial pressure of feed gas up to 800 Torr. Figures 2 and 3 show the results for pure gas and air as the feed gas.

The Vycor composite membrane had a separation factor $\alpha\left(\mathrm{O}_{2} / \mathrm{N}_{2}\right)$ greater than 3 and GPR of $10^{-8}$ order. These were nearly the same properties as the membrane shown in Figure 6 of the previous paper. $\operatorname{GPR}\left(\mathrm{O}_{2}\right)$ decreased more rapidly with increase of feed gas pressure up to 800 Torr than $\operatorname{GPR}\left(\mathrm{N}_{2}\right)$ did. This may be because the isothermal $\mathrm{O}_{2}$ sorption curve of poly $(N$-methylpyrrole) had large pressure dependence as shown in Figure 2 of the previous paper. In other words, $\mathrm{d} C_{\mathrm{s}} / \mathrm{d} P$ in eq 2 is not constant, but decreases with pressure. $\operatorname{GPR}\left(\mathrm{N}_{2}\right)$ for pure gas is nearly constant with the feed gas pressure, but for mixed gas (air), it increases with decrease of pressure. The increase corresponds to larger decrease of $\operatorname{GPR}\left(\mathrm{O}_{2}\right)$ with pressure for mixed gas than for pure gas.

Some interactions may occur between two component, $\mathrm{O}_{2}$ and $\mathrm{N}_{2}$, during surface flow. The component of slower flow, $\mathrm{N}_{2}$, is speeded up by the component of faster flow, $\mathrm{O}_{2}$ and the component of faster flow, $\mathrm{O}_{2}$, is slowed down by the component of slower flow, $\mathrm{N}_{2}$. So in the mixed gas the separation factor $\alpha$ becomes small.

Shinoda et al. ${ }^{6}$ reported the separation of organic vapors through Vycor glass. In their report, GPR and $\alpha$ showed much smaller values with mixed vapors than those with unmixed vapors. For the composite membrane here, some decrease of GPR and $\alpha$ was observed with mixed gas, but the degree of decrease was relatively small compared with the results of organic vapors.

Koros et $a .^{7}$ analyzed theoretically the mechanism of gas permeation through glassy polymers by dual-mode sorption model. In the model, the diffusion of gas in a glassy polymer was expressed by the summation of two terms. One is the diffusion of molecules dissolved into polymer with Henry's law and the other is the one adsorbed on the surface of micro-void in glassy state by Langmuir mode. For permeation of mixed gas containing easily condensable gases such as $\mathrm{CO}_{2} / \mathrm{He}$ and $\mathrm{CO} / \mathrm{H}_{2}$, they showed theoretically the same pressure dependence of 
GPR as observed in our system, though the surface flow model in our study should be distinguished from the partial immobilization model of Koros et al. Although $\mathrm{O}_{2}$ and $\mathrm{N}_{2}$ are noncondensable gases, $\mathrm{O}_{2}$ molecules are considered to be adsorbed on the surface of poly $(N$-methylpyrrole) with multilayer as shown in Figure 1(b). Koros et al. pointed out the effect of introduction of a contamitant $\left(\mathrm{H}_{2} \mathrm{O}\right)$ in the feed gas on GPR. In general, $\mathrm{H}_{2} \mathrm{O}$ has a high affinity for a surface and easily condenses, so it deteriorates GPR and $\alpha$ of a membrane. When GPR of the composite membrane No. 4 in Table I was measured with air of $41 \%$ relative humidity, $\operatorname{GPR}\left(\mathrm{O}_{2}\right)$ was $2.91 \times 10^{-6}$ and $\alpha$ was 1.24 . So $\operatorname{GPR}\left(\mathrm{O}_{2}\right)$ was reduced to about a half that obtained with dry air.

Similarly, the effect of feed gas pressure on GPR were investigated with the ceramic composite membrane (No. 5 in Table I). The results shown in Figure 4 are quite similar to those of the Vycor glass composite membrane in Figure 3.

\section{Variation of GPR with Temperature}

As composite membranes consist of an

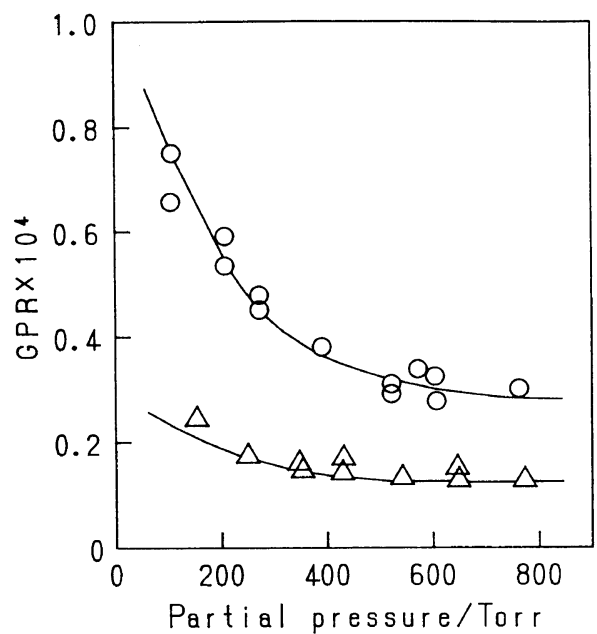

Figure 4. GPR vs. feed gas pressure for the ceramic composite membrane (No. 5): feed gas, air; (O), $\operatorname{GPR}\left(\mathrm{O}_{2}\right)$; $(\triangle), \operatorname{GPR}\left(\mathrm{N}_{2}\right)$. inorganic support, they are expected to have heat resistant properties. GPRs of the ceramic composite membrane were measured at $1 \mathrm{~atm}$ ( 760 Torr) with air as feed gas varying the temperature from room temperature up to $120^{\circ} \mathrm{C}$. As shown in Figure 5, GPR $\left(\mathrm{O}_{2}\right)$ and $\operatorname{GPR}\left(\mathrm{N}_{2}\right)$ monotonously increased with temperature up to $c a .80-100^{\circ} \mathrm{C}$, but was saturated above the temperature. The separation factor $\alpha$ in Figure 6 decreased with temperature up to $c a .100^{\circ} \mathrm{C}$ and was nearly constant above this temperature. It is remarkable that the composite membranes showed excellent high permselectivity èven at $120^{\circ} \mathrm{C}$, for it is difficult to obtain organic polymer membranes having such heat resistance.

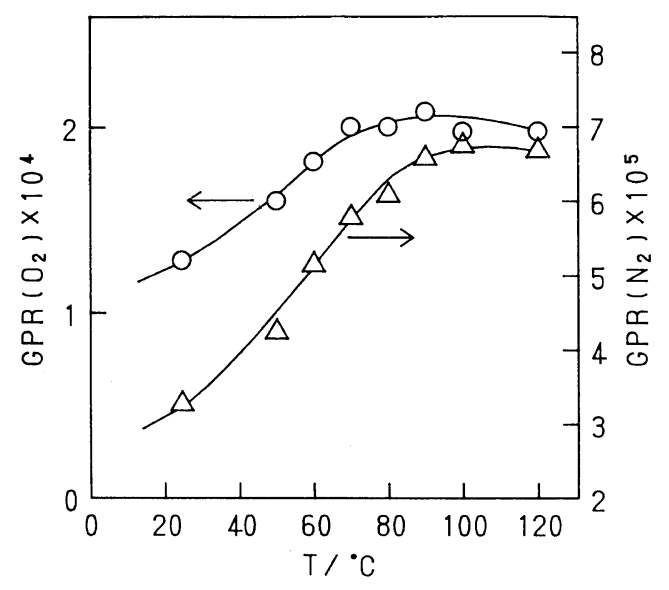

Figure 5. GPR vs. temperature for the ceramic composite membrane (No. 5): feed gas, air; $(\mathrm{O}), \operatorname{GPR}\left(\mathrm{O}_{2}\right) ;(\triangle)$, $\operatorname{GPR}\left(\mathrm{N}_{2}\right)$.

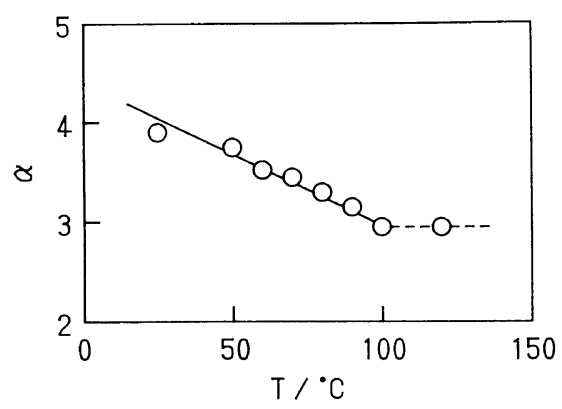

Figure 6. Separation factor $\alpha\left(\mathrm{O}_{2} / \mathrm{N}_{2}\right)$ vs. temperature for the ceramic composite membrane (No. 5): feed gas, air. 


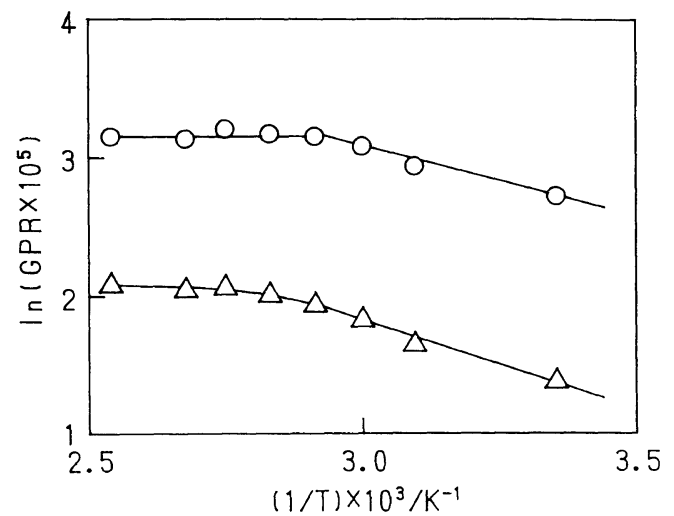

Figure 7. GPR vs. $(1 / T)$ for the ceramic composite membrane (No. 5): feed gas, air; $(\bigcirc), \operatorname{GPR}\left(\mathrm{O}_{2}\right) ;(\triangle)$, $\operatorname{GPR}\left(\mathrm{N}_{2}\right)$.

As a gas flow through the composite membrane is considered to occurr with the two mechanism, surface flow and Knudsen flow, increase of GPR with temperature is caused by increase of the surface diffusion coefficient $D_{\mathrm{S}}$ as expressed by eq 1 and 2, but Knudsen flow proportional to $(T)^{-1 / 2}$ decreases with temperature. This may be one of the reason why the increase of GPR with temperature was saturated at high temperature. Another important factor is the temperature dependence of $\left(\mathrm{d} C_{\mathrm{S}} / \mathrm{d} P\right)$ in eq 2 . In general, an adsorption process is exothermic, so $\left(\mathrm{d} C_{\mathrm{S}} / \mathrm{d} P\right)$ may decrease with temperature resulting in decrease of GPR. Moreover, if the gas flow through the composite membrane is dominated by Knudsen flow, the separation factor $\alpha$ might increase with temperature, which is contrary to the experimental results.

So it is concluded that the gas flow through the composite membrane, No. 5, is dominated by surface flow giving a high performance membrane.

To estimate the activation energy according to eq 2, Arrhenius plots are shown in Figure 7, where nearly straight lines are obtained below $c a .70^{\circ} \mathrm{C}$. The apparent activation energies of diffusion were evaluated to be $E\left(\mathrm{O}_{2}\right)=8.3\left(\mathrm{~kJ} \cdot \mathrm{mol}^{-1}\right)$ and $E\left(\mathrm{~N}_{2}\right)=11(\mathrm{~kJ}$. $\left.\mathrm{mol}^{-1}\right)$.

\section{CONCLUSION}

Comparing GPR of the ceramic composite membrane having a thin active layer with that of the Vycor composite membrane, it was experimentally proven that GPR of the membrane, through which gas permeated with the mechanism of surface flow, was proportional to the inverse of the effective membrane thickness without reduction of permselectivity. Thus, it is possible to design a gas separation membrane of high performance by modifying an adequate micro-porous medium with conducting polymers such as poly $(N$-methylpyrrole).

Another advantage of the composite membrane is that it provides good heat resistance not easily attainable with polymeric membranes. One disadvantage of the composite membrane is that GPR and $\alpha$ deteriorate in the presence of condensable vapors such as water, but this can be overcome in practical applications.

Acknowledgement. We acknowledge Dr. H. Yoshimizu of Nagoya Institute of Technology for providing permeability coefficient data.

\section{REFERENCES}

1. K. Kamada, J. Kamo, A. Motonaga, T. Iwasaki, and H. Hosokawa, Polym. J., 26, 141 (1994).

2. M. Uchida, T. Hirai, J. Kamo, H. Yoshida, and K. Kamada, Prepr., 3rd SPSJ International Polymer Conference, Nagoya, November 26, 1990, p 42.

3. Catalog, issued by Toshiba Ceramic Co., Ltd. (1987).

4. H. Yoshimizu, K. Takagi, Y. Tsujita, and T. Kinoshita, Polym. Prepr., Jpn., 42, 1294 (1993) and private communication.

5. Y. Horiguchi, R. R. Hudgins, and P. L. Silveston, Can. J. Chem. Eng., 49, 76 (1971).

6. S. Shinoda, K. Kubo, T. Arai, and Y. Saito, Maku, 12, 454 (1987).

7. W. J. Koros, R. T. Chern, V. Stannett, and H. B. Hopfenberg, J. Polym. Sci., Polym. Phys. Ed., 19, 1513 (1981). 